\title{
REFLEXÕES SOBRE A ÉTICA DO DISCURSO
}

\section{Flávio Beno Siebeneichler}

\section{Resumo}

A ética do discurso se caracteriza como uma posição filosófica que lança mão de um procedimento argumentativo, também caracterizado como discurso, a fim de solucionar problemas, dilemas ou conflitos morais na atual sociedade complexa, globalizada e multicultural. A ética do discurso tem sua origem nos trabalhos teóricos de Karl-Otto Apel e Jürgen Habermas. A ética do discurso, que constitui uma moral discursiva talhada para a vulnerabilidade de seres vivos que se individuam mediante socialização e comunicação, precisa resolver, ao mesmo tempo, duas tarefas: de um lado, postular respeito simétrico pela dignidade de cada um e, por outro, proteger as relações intersubjetivas através das quais os indivíduos se mantem como membros de uma comunidade. Habermas propoê um novo caminho, genealógico, cuja meta é a reconstrução crítica e hermenêutica do conteúdo deontológico inerentes a valores, normas, mandamentos e intuições éticas vigentes em uma sociedade.

Palavras-chave: Karl-Otto Apel, ética do discurso, hermenêutica, genealogia

\begin{abstract}
Abstract

The ethics of discourse is characterized as a philosophical position that makes use of an argumentative procedure, also characterized as discourse, in order to solve problems, dilemmas or moral conflicts in today's complex, globalized and multicultural society. The ethics of discourse has its origin in the theoretical works of Karl-Otto Apel and Jürgen Habermas. The ethics of discourse, which constitute a discursive morality tailored to the vulnerability of living beings that are individuated through socialization and communication, must at the same time solve two tasks: on the one hand, to posit symmetrical respect for the dignity of each one, and for another, to protect the intersubjective relationships through which individuals maintain themselves as members of a community. Habermas proposes a new path, genealogical, whose goal is the critical and hermeneutic reconstruction of deontological content inherent in ethical values, norms, commandments and intuitions in a society.
\end{abstract}

Keywords: Karl-Otto Apel, ethics of discourse, hermeneutics, genealogy 


\section{PRÓLOGO}

\subsection{FENOMENOLOGIA DO MUNDO ÉTICO/MORAL}

Vivemos imersos num mundo ético e moral, em grande parte invisível, o qual pode exteriorizar-se de várias maneiras:

1) Na linguagem do dia-a-dia.

Nosso mundo ético e moral transparece em vocábulos da linguagem comum configurando-se em um vocabulário extremamente rico e variado, o qual assume, geralmente, a figura de um código binário: bom - mau; justo - injusto; veraz - falso; íntegro - corrupto; digno - indigno; solidário - egoísta; corajoso - covarde; honesto - desonesto, etc.

2) Numa vasta e intrincada gama de sentimentos especialmente os seguintes:

a. O sentimento de compaixão pelo outro. Esse sentimento possui um elemento cognitivo tendo em vista que nele se manifesta a convicção de que o outro que está sofrendo tem uma pretensão legítima a não sofrer o que está sofrendo. $\mathrm{O}$ sentimento de compaixão - como também o sentimento de desrespeito ou de agravo - são sentimentos de alguém que é membro de uma comunidade e que implicam uma relação simétrica de expectativas normativas. Quem sente compaixão tem a impressão de ser um participante.

b. O ressentimento. Esse sentimento também vem acompanhado de um elemento cognitivo. Entretanto, neste caso, a própria pessoa está convencida de que está sofrendo uma injustiça cometida por outro.

c. O sentimento de culpa. Quem se sente culpado reconhece que praticou algo não justificável perante a própria consciência. Tal sentimento pode provocar, por sua vez:

d. O sentimento de vergonha. Quando sentimos vergonha nos reconhecemos como uma pessoa desprezível pelo fato de termos cometido uma ação indevida. É interessante observar que tanto o sentimento de vergonha como o de culpa só se 
manifestam numa pessoa responsável e capaz de assumir convicções éticas ou morais próprias.

e. O sentimento de indignação. Quem possui esse sentimento se qualifica como representante de uma comunidade moral universal. Isso porque a pessoa que se indigna do ponto de vista moral não é levada a isso apenas em nome de alguém que foi ferido moralmente ou agravado. Mas em nome de algo mais geral, universal, que está sendo ferido ou ultrajado neste caso particular.

3) Em problemas ou dilemas morais.

O ser humano dotado naturalmente de sentimentos éticos e morais e que é capaz de se posicionar quanto a ações éticas ou morais mediante a emissão de juízos morais se vê, mesmo assim, envolto em graves problemas e paradoxos ético-morais cuja solução parece impossível. Cito apenas alguns exemplos: A guerra, a eutanásia, o aborto a eugenia, etc.

\subsection{SOBRE O PAPEL DO FILÓSOFO EM RELAÇÃO AO MUNDO ÉTICO E MORAL}

É sabido que os filósofos não possuem nenhum tipo de acesso privilegiado ao mundo ético e moral, tendo em vista que os valores, as normas, etc., se configuram independentemente dele. Neste caso convém perguntar: qual a importância da filosofia para ética e a moral?

A história da filosofia com F maiúsculo nos revela que ela, apesar de sua impotência em termos de geração de normas e valores éticos pode prestar, mesmo assim, um serviço relevante em termos de interpretação, de elaboração de critérios e de crítica dos pontos de vista éticos e morais. Neste cenário destacam-se dois princípios filosóficos que geralmente são tomados como paradigmas quando se reflete sobre o mundo ético e moral:

a) O princípio da felicidade ou sumo bem, elaborado por Aristóteles, segundo o qual todos os indivíduos buscam, acima de tudo, a felicidade deles próprios e das comunidades às quais pertencem.

b) O princípio do dever incondicional, elaborado por Kant. Segundo ele, o homem não pode tomar a felicidade como diretriz das ações éticas. Isso porque sua razão é finita e incapaz de antecipar todos os objetivos e as ações que poderiam tornar sua vida realmente feliz. Somente um deus seria capaz disso!

Entretanto, Kant também sabe que a única coisa que a razão humana finita pode reconhecer universalmente como boa é a boa vontade, a qual implica, segundo ele, a idéia de 
um dever moral incondicional, ou seja, um imperativo categórico. Tal imperativo constitui uma lei universal capaz de servir como princípio para uma vontade absolutamente boa.

Convém ressaltar, ainda, que o paradigma kantiano se configura em termos intersubjetivos, pois, abrange todas as pessoas sem exceção de ninguém. Seu critério não é a felicidade, minha ou de meu grupo, mas a justiça e o respeito pela humanidade em geral.

\subsection{CONSIDERAÇÕES GERAIS SOBRE A ÉTICA DO DISCURSO}

A ética do discurso se caracteriza como uma posição filosófica que lança mão de um procedimento argumentativo, também caracterizado como discurso, a fim de solucionar problemas, dilemas ou conflitos morais na atual sociedade complexa, globalizada e multicultural. Ela somente entra em ação, por assim dizer, quando há conflitos reais sobre normas. Mas não tem como objetivo a criação de princípios éticos ou normas morais. Ela apenas estabelece como critério um princípio discursivo ou princípio D.

De outro lado, ela introduz uma distinção rígida entre ética e moral. Segundo esta linha de pensamento, as questões éticas têm de ser entendidas no sentido da ética de Aristóteles, isto é, enquanto questões referentes à felicidade e às preferências valorativas de uma pessoa ou de um grupo.

Ao passo que as questões morais envolvem o dever de respeitar a todos os seres humanos sem exceção.

Disso resulta que a ética do discurso, cujo nome correto deveria ser "moral do discurso" toma como ponto de partida o imperativo categórico kantiano, o qual é, todavia, submetido a um procedimento de destranscendentalização, conforme veremos mais adiante.

\section{GÊNESE DA ÉTICA DO DISCURSO NAS TEORIAS DE KARL-OTTO APEL E JÜRGEN HABERMAS}

A ética do discurso tem sua origem nos trabalhos teóricos de Karl-Otto Apel e Jürgen Habermas que constituem exemplo único de parceria e de crítica mutua no horizonte da filosofia contemporânea.

A versão apeliana da ética do discurso surge mais cedo, em 1973, inserida no contexto de um trabalho mais amplo sobre a transformação transcendental e pragmática da filosofia, o qual se inspira na semiótica de Charles S. S. Peirce e se delineia como um "apriori ético transcendental" pressuposto em toda e qualquer prática de argumentação (APEL, 1973). 
Ao passo que o primeiro trabalho explícito de Habermas sobre esse tema vem a público somente dez anos mais tarde, em 1983, na esteira de sua obra-mestra sobre o agir comunicativo. Neste texto ele redige "apontamentos pragmático-formais" destinados a um possível programa de fundamentação de uma ética mediante procedimentos discursivos.

É interessante constatar que, a partir desse início ocasional, de qualquer modo não previsto na arquitetura da teoria do agir comunicativo de Habermas nem na pragmática transcendental de Apel, a ética do discurso firmou-se como um dos temas centrais das reflexões dos dois filósofos e de outros teóricos, de várias especialidades, que passaram a analisá-la e a discuti-la. Essa crítica provocou naturalmente os iniciadores da ética do discurso a tomar posição mediante esclarecimentos, aprofundamentos, réplicas e, inclusive, correções.

Não obstante isso ou, talvez, por causa disso, a ética do discurso prosperou. Em 1986, ao fazer um balanço do caminho andado, Apel pode constatar, com indisfarçável satisfação, que a "ética da comunicação" fundada por ele e por Habermas, conseguira sobreviver a várias rodadas de discussão, as quais tinham contribuído para o aprimoramento dos respectivos princípios teóricos (APEL, 1986).

Tal otimismo, no entanto, vai ser quebrado abruptamente anos mais tarde, em 1998, no momento em que Apel constata que o texto de Habermas sobre Direito e democracia, publicado em 1992, estava colocando em risco a integridade da ética do discurso projetada por ambos. A preocupação de Apel nesse momento é tamanha que chega a falar na necessidade de salvar a ética do discurso que teria sido posta a perder por um "sociologismo" inerente à mencionada obra de Habermas (APEL,1998).

Não pretendo aprofundar, aqui, as diferenças entre Habermas e Apel no tocante à ética do discurso. Limito-me a chamar a atenção para um dos aspectos mais intrigantes e surpreendentes da teoria discursiva da ética, a saber, o seu caráter de projeto provisório, inconcluso, que provoca mais dissensos do que propriamente consenso, inclusive entre os seus fundadores pós-kantianos.

Segundo Habermas, as diferenças entre ele e Apel são conseqüência das pretensões teóricas de ambos: a de Apel é fortemente transcendental ${ }^{1}$. Ao passo que o método de Habermas persiste em uma linha destranscendentalizada. Entretanto, parece que o laço que une esses dois traçados arquitetônicos muitas vezes é obstaculizado por fatores extrateóricos. Habermas expressa bem este estado de coisas na seguinte passagem:

\footnotetext{
${ }^{1}$ Apel não faz segredo disso. No prefácio escrito especialmente para a tradução francesa de seu texto sobre o Apriori da comunidade de comunicação ele afirma textualmente: "Meu pensamento [...] após um derradeiro desvio pelo pragmatismo de Charles Peirce, encetou o caminho de volta para uma retranscendentalização".
} 
Na comparação de teorias, cujas intenções se aproximam tanto, falta, muitas vezes, aos que dela participam diretamente o fôlego hermenêutico necessário para que um possa acompanhar, a partir da distância requerida, os argumentos do outro. No meu entender, os elementos que existem em comum interferem tanto na elaboração da crítica, que ambos interrompem prematuramente a palavra um do outro, aduzindo precipitadamente argumentos próprios. (HABERMAS, 2005, p.84)

Para corroborar a proximidade entre Apel e Habermas é necessário destacar que os dois projetos repousam sobre elementos comuns, a saber: Em primeiro lugar, a linha de argumentação é decididamente pós-metafísica delineada na perspectiva de uma filosofia da linguagem vertida em termos pragmáticos. Em segundo lugar, a moral do discurso formulada por ambos não constitui uma reação moral a perigos iminentes que colocariam em risco a sobrevivência da humanidade e da natureza, como é o caso da "ética da responsabilidade" cultivada por Hans Jonas (1979). Ela também não pretende fornecer conteúdos normativos para a sociedade em geral, a exemplo de John Rawls (1971). Ela se configura, ao invés disso, como reflexão tipicamente filosófica de cunho cognitivista delineada nos termos de um paradigma pragmático e hermenêutico do uso da linguagem em geral.

Em última instância, ela tem a pretensão de abordar e, quiçá, solucionar o problema fundamental da razão prática kantiana que pode ser formulado nos seguintes termos: "o que devo fazer quando estou envolvido em um conflito moral?” ou, “o que devemos fazer?”, ou ainda: "é possível fundamentar racionalmente normas morais obrigatórias capazes de solucionar conflitos normativos no campo da ação humana?". "De que tipo seriam essas normas?"

Por conseguinte, o oponente principal da ética do discurso, a ser convencido mediante argumentos, não é a pessoa cega ou indiferente aos perigos que a humanidade está correndo como quer Hans Jonas - mas principalmente o cético radical, o cínico e o relativista, que não aceitam a possibilidade de uma demonstração racional de deveres morais obrigatórios.

Em que pese isso, convém notar que Habermas e Apel sempre tiveram a clara consciência de que a ética do discurso constitui nada mais que um programa e um projeto provisório, um verdadeiro experimento nas palavras de Apel, ou ainda, um plano geral para uma construção em vias de realização, apoiado em pretensões de validade a serem discutidas racionalmente. Os próprios títulos da maioria dos textos elaborados neste sentido trazem as marcas da provisoriedade: "Apontamentos para um programa de fundamentação da ética do discurso" (Habermas, 1983); "Esclarecimentos sobre a ética do discurso" (Habermas, 1991); “Confrontos na experimentação do princípio pragmático-transcendental” (Apel, 1998); "Pequena réplica a uma grande controvérsia" (Habermas, 2005). 
Hoje em dia poderíamos refazer os balanços levados a cabo por Apel em 1986 e 1998 afirmando que a situação da ética do discurso não mudou muito de lá para cá. Durante os seus mais de trinta anos de existência conturbada e questionada ela, que continua se orientando pela ideia de uma teoria do entendimento, jamais gozou de consenso pleno! As inúmeras rodadas de discussão que contaram com ampla participação de pensadores das mais variadas orientações teóricas de praticamente todos os continentes, inclusive do Brasil, tampouco proporcionaram a elaboração de um sistema unitário. Antes, pelo contrário e apesar de tentativas interessantes de sistematização, predominam as diferenças de versões concorrentes (SIEBENEICHLER, 2000).

\section{DESDOBRAMENTOS DA ÉTICA DO DISCURSO NA PERSPECTIVA DE JÜRGEN HABERMAS}

Nos "Apontamentos para um programa de fundamentação de uma ética do discurso", redigidos em 1983, Habermas complementou o "princípio da argumentação em geral", introduzido por Apel, por um princípio do discurso " $\mathrm{D}$ ” a ser interpretado, no entanto, de modo mais parcimonioso, "econômico": "somente podem pretender validade normas que, em princípio, poderiam merecer o assentimento de todos os possíveis afetados por elas enquanto participantes de um discurso prático" (HABERMAS, 1983, p.103).

Habermas chegou a esta fórmula estimulado, não somente por Apel, mas também por um trabalho de F. Kambartel que criara, em 1974, uma fórmula semelhante. Segundo ele, podemos considerar "fundamentadas em um diálogo racional as normas com as quais todos os possíveis afetados por elas puderem consentir" (HABERMAS, 1983, p.103, nota 73). Habermas reconhece também que o seu princípio do discurso recebeu reforços consideráveis de R. Alexy que chegou a estabelecer, em sua teoria sobre o discurso prático, um catálogo de pressuposições inevitáveis no processo da argumentação (HABERMAS, 1983).

Ele sugeriu, além disso, um novo princípio de universalização (U), cuja formulação textual é a seguinte:

Uma norma controvertida entre participantes de um discurso prático somente pode obter assentimento caso U seja válido, isto é, se as consequências e efeitos colaterais - que provavelmente afetarão a satisfação dos interesses de cada um caso a norma controvertida venha a ser obedecida por todos - puderem ser aceitos por todos sem nenhum tipo de coação. (HABERMAS, 1983, p.103)

A introdução do princípio U é necessária, segundo Habermas, uma vez que, em condições pós-metafísicas, não é possível extrair diretamente normas morais fundamentais das 
pressuposições gerais da argumentação discursiva. E neste ponto ele discorda de Apel (HABERMAS, 1983).

Por conseguinte, a ética do discurso ou teoria discursiva da moral se coloca como um empreendimento que não pode, em nenhum momento, dar-se por satisfeito, tendo em vista que a pretensão inerente à tese que defende, a saber, o princípio U, é de cunho universalista.

De outro lado, porém, os argumentos que sustentam tal pretensão universalista possuem status teórico relativamente reduzido. Por esta razão, a fundamentação do ponto de vista moral passará a ser o ponto mais marcante, a tarefa principal e também o fardo mais pesado da teoria discursiva da moral.

Ora, os trabalhos posteriores relativos a esse tema se configuram como tentativas argumentativas reiteradas de resgate desta tarefa multifacetada de defesa do princípio U tendo em vista novas objeções (HABERMAS, 1996). E esse trabalho obedece a duas grandes estratégias. A primeira consiste em mostrar a razoabilidade de $\mathrm{U}$ mediante análise das pressuposições da argumentação em geral; enquanto que a segunda segue os passos de um questionamento genealógico.

\subsection{ANÁLISE DAS PRESSUPOSIÇÕES DA ARGUMENTAÇÃO}

A sua linha de argumentação nesse contexto obedece ao seguinte esquema: ele introduz abdutivamente o princípio de universalização (U) como uma regra de argumentação para discursos práticos, que pode ser fundamentada, segundo ele, a partir do conteúdo das pressuposições pragmáticas de uma argumentação razoável e mediante um esclarecimento do sentido de pretensões de validade normativas que acompanham inevitavelmente ações orientadas por entendimento (HABERMAS, 1983). ${ }^{2}$

A seguir, Habermas tenta fundamentar a validade transcultural de U lançando mão das mesmas pressuposições gerais e necessárias da argumentação comprovadas pelo argumento pragmático-transcendental no sentido de Apel. Entretanto, ele conclui que, dado o fato de que o argumento pragmático-transcendental não possui mais, nos projetos de ambos, o sentido a priorístico de uma dedução transcendental no sentido de Kant, ele apenas faz jus ao fato de que não dispomos de alternativas melhores para nosso modo de argumentar. E por isso mesmo, uma

\footnotetext{
${ }^{2}$ É interessante notar que tal abdução do princípio de universalização se inspira no modelo do "reflective equilibrium", de J. Rawls, que constitui uma reconstrução daquelas intuições cotidianas que subjazem a toda avaliação imparcial de conflitos envolvendo ações morais.
} 
moral fundada sobre tais princípios não consegue ser mais do que mera reconstrução racional hipotética, a qual deve estar, por si mesma, aberta a outras teorias semelhantes, já que depende de uma comprovação indireta através delas (HABERMAS 1983).

A estratégia habermasiana de inferir $U$ de pressuposições gerais e necessárias da argumentação vai ser alvo de uma crítica por parte de Albrecht Wellmer, Charles Taylor e outros autores.

A sua reação a essas críticas se deposita nos Esclarecimentos sobre a ética do discurso, escritos em 1991, onde ele afirma expressamente que pretende dar continuidade ao projeto contido nos Apontamentos de 1983 levando na devida conta objeções levantadas (HABERMAS, 1991).

No meu entender, há dois pontos a merecer destaque nesses esclarecimentos. Em primeiro lugar, Habermas se dá conta, após as provocações dos seus críticos, de que o princípio do discurso D, que ele julgava bem fundamentado, estava a exigir reforços. Por isso ele tenta soletrar o problema de fundamentação da ética do discurso - que ele reconhece ser complexo e complicado - em termos de uma analogia entre correção de normas morais e pretensão à verdade embutida em proposições assertóricas (HABERMAS,1991). A partir daqui, o modo preferencial de formular o problema da ética do discurso passa a ser: Até que ponto e como é possível fundamentar enunciados normativos? Não pretendo desenvolver esse ponto e sim chamar a atenção para um segundo tema, surpreendente, que domina os referidos Esclarecimentos.

Trata-se do papel desempenhado por intuições morais na ética do discurso: até que ponto o esclarecimento do ponto de vista moral ou princípio de universalização $U$, adotado pela ética do discurso, é capaz de expressar de modo mais ou menos adequado nossas intuições morais fundamentais que são substanciais e, por conseqüência, não podem ser geradas por nenhum tipo de procedimento discursivo? (HABERMAS, 1991)

Para Habermas, intuições morais fornecem compreensões ou intelecções sobre regras e normas que garantem o melhor modo de nos portarmos a fim de proteger e compensar a extrema vulnerabilidade das pessoas humanas, a qual deriva de formas de vida socioculturais. A necessidade de proteção deriva do fato de que os sujeitos humanos são seres que se individualizam pelo caminho de uma socialização, isto é, são sujeitos que possuem a faculdade da fala e da ação e se constituem, ao mesmo tempo, como indivíduos e como membros de uma comunidade lingüística à proporção que crescem em um mundo da vida compartilhado intersubjetivamente. 
Na perspectiva da teoria do agir comunicativo, as identidades de um sujeito particular e da coletividade se formam e se mantem de modo co-originário em processos de comunicação. E quanto mais as estruturas culturais de uma comunidade se diferenciam ou se racionalizam, tanto mais claramente é possível perceber que o processo de autodeterminação de um indivíduo depende de vários fatores e ordens sociais. Em termos hegelianos: a pessoa só pode constituir um centro de intimidade subjetiva à proporção que se aliena, ao mesmo tempo, em relações interpessoais que, segundo Habermas, formam-se mediante comunicação. Isso explica a vulnerabilidade da identidade da pessoa e da comunidade, a qual precede, inclusive, a vulnerabilidade da integridade biofísica da pessoa humana (HABERMAS, 1991). ${ }^{3}$

Por isso, a ética do discurso, que constitui uma moral discursiva talhada para a vulnerabilidade de seres vivos que se individuam mediante socialização e comunicação, precisa resolver, ao mesmo tempo, duas tarefas: De um lado, postular respeito simétrico pela dignidade de cada um, isto é, fazer valer a intocabilidade dos indivíduos. A essa tarefa corresponde o princípio da justiça em sentido moderno, isto é, o princípio que se refere a iguais direitos e à liberdade subjetiva de indivíduos insubstituíveis.

A outra tarefa consiste em proteger as relações intersubjetivas através das quais os indivíduos se mantem como membros de uma comunidade. E isso só é possível graças ao princípio da solidariedade que exige empatia e cuidado com o bem-estar dos outros e dos "camaradas" irmanados em uma forma de vida compartilhada intersubjetivamente ${ }^{4}$. Habermas pensa ser possível estabelecer um nexo entre esses dois princípios morais que historicamente estão na base de tradições contrárias, a saber: as assim chamadas éticas de bens de origem aristotélica, conforme vimos mais acima, que se "especializam" em questões relativas ao bem comum. E as éticas do dever focalizadas no princípio da justiça. E neste particular, ele se ampara no conceito de eticidade, de Hegel, que é contrário à separação entre o universalismo abstrato contido no princípio da justiça e o particularismo inerente ao princípio do bem comum.

Podemos concluir, pois, que a ética do discurso tenta extrair da própria atividade comunicativa, que é causa da vulnerabilidade de sujeitos socializados, pontos de vista essenciais para uma compensação dessa fragilidade (HABERMAS, 1991). Porquanto esse projeto

\footnotetext{
${ }^{3}$ Lutz Wingert compartilha tal concepção intersubjetivista da moral. Ele desenvolve a ideia de uma teoria moral do duplo respeito universal, isto, é, o respeito pelo indivíduo moral vulnerável e insubstituível em seu juízo moral e o respeito pelos membros da comunidade que possuem iguais direitos de crítica. Cf. WINGERT, L. Gemeinsinn und Moral. Grundzüge einer intersubjektivistischen Moralkonzeption. Frankfurt/M.: Suhrkamp, 1993, 268.

${ }^{4}$ Em uma obra que surgiu quase na mesma época que os Esclarecimentos à ética do discurso, Habermas argumenta que essas tarefas ultrapassam, inclusive, a competência da moral, necessitando de uma complementação pelo princípio da democracia e do direito. Cf. HABERMAS, J. Faktizität und Geltung. Beiträge zur Diskustheorie des Rechts und des demokratischen Rechtsstaats. Frankfurt/M.: Suhrkamp, 1992.
} 
discursivo se inspira em idéias básicas que podem ser inferidas de condições de simetria e de expectativas de reciprocidade inerentes a uma prática comunicativa cotidiana.

Habermas, no entanto, distingue dois tipos elementares de atividade comunicativa ou práxis cotidiana: o agir comum orientado por entendimento mútuo; e o discurso que constitui uma forma de comunicação mais pretensiosa na qual as pressuposições do agir orientado por entendimento podem ser generalizadas à luz da ideia de uma comunidade de comunicação ideal que inclui todos os sujeitos dotados da faculdade de fala e de ação.

Tal distinção the permite afirmar que a ética do discurso, apesar de construída sobre o princípio D - que é um conceito de cunho procedimental - tem condições de atingir elementos substanciais, éticos: "O discurso prático é capaz de garantir - graças às suas características pragmáticas - um tipo de formação da vontade que abre espaço para o respeito dos interesses de cada sujeito sem romper o elo social que une cada um a todos os outros" 5 (HABERMAS, 1991,p.18). Isso sugere a possibilidade de pensar um conceito deontológico de justiça mais amplo do que o elaborado por Kant e capaz de englobar aspectos estruturais de uma vida boa lançando mão de pontos de vista gerais da socialização comunicativa em geral (HABERMAS, 1991).

Habermas, porém, não se satisfaz com os resultados obtidos por esse caminho dedutivo que visa robustecer o princípio de universalização $U$ a partir de pressuposições inevitáveis de uma prática argumentativa em geral. Ele arrisca por isso, um novo caminho, genealógico, cuja meta é a reconstrução crítica e hermenêutica do conteúdo deontológico inerentes a valores, normas, mandamentos e intuições éticas vigentes em uma sociedade.

\subsection{ESTRATÉGIA DO QUESTIONAMENTO GENEALÓGICO}

A inspeção genealógica de Habermas chega a três conclusões:

$1^{\text {a) }}$ Existe na pré-modernidade uma moral comum explicitada no Decálogo e na lei do amor cristão. Esta moral se apoia num fundamento cuja pretensão de validade é absoluta, uma vez que se trata de um Deus transcendente, criador, salvador, omnisciente e onipotente. Ela se resume no igual respeito por cada um e na solidariedade, a qual inclui a todos, sem exceção de ninguém. Segundo Habermas, pelo fato de se apoiar na autoridade de um Deus justo e omnisciente, esta moral reveste-se de elementos epistêmicos ou cognitivos.

\footnotetext{
${ }^{5}$ Karl-Otto Apel lembra, nesse contexto, que o conteúdo da "comunidade de comunicação ideal” consiste precisamente no fato de que cada um, enquanto participante de um discurso, depende apenas de si mesmo e, ao mesmo tempo, esta inserido em uma relação universal.
} 


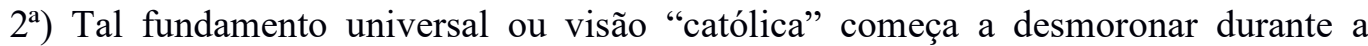
modernidade cedendo o lugar a sociedades pós-tradicionais ou pós-metafísicas.

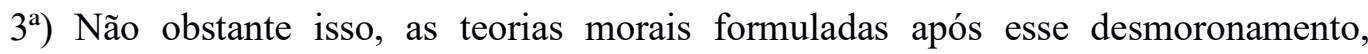
especialmente as que brotaram do utilitarismo, do contratualismo e do kantismo podem ser interpretadas, mesmo assim, como tentativas de reconstrução malsucedidas do conteúdo nuclear da visão moral tradicional.

Nesse ponto cabe a pergunta: até que ponto a genealogia habermasiana, desenvolvida na perspectiva da ética do discurso, consegue realmente resgatar elementos das intuições religiosas originais da ética ocidental?

Sobre este ponto é necessário lembrar, em primeiro lugar, que a genealogia não é capaz de manter intacto o conteúdo das intuições reconstruídas uma vez que não consegue salvar o sentido de validade realista das normas morais. Isso porque as práticas morais atuais não tomam mais como referência a pessoa de um Deus salvador absolutamente justo, nem condutas de vida exemplares. Além disso, não possuímos um substituto profano para a expectativa de uma salvação eterna pessoal.

Não obstante isso, a reflexão genealógica habermasiana pretende, mesmo assim, comprovar a existência de um "resto de substância moral normativa" que teria sobrevivido nas próprias sociedades pós-tradicionais e que se coagula em dois elementos fundamentais a serem mantidos em qualquer teoria moral: trata-se, de um lado, da justiça e, de outro, da solidariedade, princípios já mencionados mais acima (SIEBENEICHLER, 1998)

Convém observar, além disso, que a genealogia elaborada à luz da ética do discurso, a qual não consegue manter na íntegra o conteúdo moral das intuições morais reconstruídas, modifica o sentido de obrigatoriedade inserido em normas morais. De um lado, a passagem da perspectiva de um Deus omnisciente para a perspectiva profana do homem faz com a que a validade de normas passe a significar que elas, a partir de agora, podem contar com um assentimento de todos os afetados por elas à proporção que a examinam em comum, isto é, de modo cooperativo, e enquanto participam de discursos práticos a fim de deliberarem se uma determinada prática é do interesse simétrico de todos.

Além disso, tal passagem deixa transparecer pegadas da falibilidade e do caráter inventivo do espírito humano que é capaz, não somente de descobrir coisas, mas também de elaborar projetos e criar normas novas. De outro lado, a diferenciação entre um dever (que se refere àquilo que é moralmente correto) e o valor (que se refere àquilo que é eticamente desejável) abre espaço para a idéia de uma normatividade que só pode ser coberta mediante a formação de um juízo imparcial. E neste caso, a validade das normas morais controversas se 
coloca na dependência de um assentimento racional de todos os virtuais afetados por estas normas, os quais podem entrar em um processo argumentativo a fim de examinar conjuntamente se tal prática pode ser considerada compatível com o interesse simétrico de todos os possíveis afetados por ela.

É necessário inquirir, a seguir, se a moral fragmentária que brota de uma reconstrução genealógica dos conteúdos ético-axiológicos de uma tradição moral religiosa centrada na justiça e na solidariedade não continua presa ao conteúdo originário, o que poderia configurar um eurocentrismo. Essa questão é relevante dado o fato de que, se a ética do discurso se exaurisse nessa tradição, que é eurocêntrica, a genealogia ficaria impedida de aclarar o conteúdo epistêmico, isto é, a justificabilidade racional, de juízos morais em geral.

Habermas pensa, no entanto, que tal risco pode ser desconsiderado porquanto é possível fundamentar o próprio ponto de vista moral a partir de elementos comuns inerentes a uma "faixa ou espaço formal" que se encontra na base da prática de argumentação. Esta faixa é estreita e neutra em termos de conteúdo moral ou ético. Ela se configura, segundo Habermas, mediante elementos comuns a uma comunidade tal como, por exemplo, a ideia de justiça diluída na ideia da fundamentação e da aplicação imparcial de normas. Por isso, ela representa uma chance, não mais do que isso, para que possamos enfrentar as múltiplas visões de mundo e as diferentes idéias de bem comum, dado o fato de que ela abre a perspectiva de um elemento capaz de assumir a tarefa de fundamentação do ponto de vista moral. (HABERMAS,1996)

Vale a pena acompanhar os passos seguidos por Habermas na fundamentação de sua genealogia.

\section{VISUALIZAÇÃO DO PROCESSO ARGUMENTATIVO DE FUNDAMENTAÇÃO DE NORMAS MORAIS}

No texto sobre a genealogia da moral, Habermas sugere um procedimento de fundamentação argumentativa em sete passos sucessivos:

1 - Os participantes de uma comunidade pós-tradicional se encontram numa situação embaraçosa, problemática, já que se vêem obrigados a resolver um conflito sobre normas comuns, cotidianas, e não podem mais contar com uma tradição comum capaz de servir como critério para estabelecer a legitimidade dessas normas. Decidem, então, lançar mão do critério do entendimento (HABERMAS, 1996).

2 - Isso implica, em primeiro lugar, a necessidade de desenvolver, a um nível ou base profana, uma autocompreensão ética e moral comum. 
3 - Entretanto, tal autocompreensão está aparentemente fadada ao fracasso, tendo em vista o fato de que as condições de vida diferenciadas de sociedades pluralistas impedem tal projeto. Os participantes descobrem que, a partir do momento em que tomam ciência de suas valorações práticas, tais valorações levam a concepções concorrentes.

4 - Suponhamos, no entanto, que eles continuam a acreditar no entendimento e que, além disso, não pretendem substituir a convivência moral, agora ameaçada, por uma simples acomodação estratégica ou por um simples modus vivendi. Neste caso, eles teriam de encontrar outro elemento possivelmente neutro capaz de ligar entre si os membros da comunidade.

5 - Entretanto, os participantes já sabem que, dada a pluralidade cultural, não existe possibilidade de um acordo sobre conteúdos normativos substanciais. Mesmo assim, eles descobrem que é possível lançar mão de um elemento que, até certo ponto, não possui conteúdo moral substancial. Trata-se do fato de que cada um deles compartilha algum tipo de forma de vida intersubjetiva, comunicativa, a qual é, ipso facto, estruturada mediante processos de entendimento lingüístico que permitem deliberações práticas. Ora, tais processos e formas de vida se revestem de características estruturais, as quais podem eventualmente ser tomadas como base para criar orientações normativas comuns dentro da comunidade.

6 - Eles descobrem, todavia, que não é possível, a partir das características de formas de vida comunicativas, justificar por que os membros de uma determinada comunidade histórica deveriam ultrapassar seus respectivos valores e normas particularistas e adotar um universalismo igualitário e inclusivo que implica relações simétricas, de inclusão e de reconhecimento recíproco.

7 - Por isso, é necessário recorrer a uma teoria que leva em conta, de um lado, a prática comunicativa cotidiana, ingênua, ao nível da qual não é possível justificar a passagem para o universalismo; e de outro lado, um processo de argumentação racional que constitui uma forma reflexiva de agir orientado por entendimento. O processo argumentativo é importante uma vez que análise do conteúdo normativo das pressuposições pragmáticas inevitáveis desse processo revela que ele se orienta inevitavelmente para algo universal que supera qualquer forma de vida particular. Isso significa que através dele o conteúdo normativo da prática comunicativa cotidiana é universalizado, desconfinado ou destravado (entschränkt) e estendido a uma comunidade universal inclusiva, a qual não exclui, em princípio, nenhum sujeito capaz de fala e ação (HABERMAS, 1996).

Deste modo, fica patente que Habermas adota a dupla estratégia porque, no seu entender, a aceitabilidade racional do princípio de universalização não depende somente de uma reconstrução pragmática do conteúdo inerente a pressuposições da argumentação, mas também 
de um conceito de normas morais obtido mediante reconstrução hermenêutica e genealógica de tradições. Além disso, a prática de argumentação discursiva constitui o ponto de convergência das duas estratégias de fundamentação do princípio de universalização: na estratégia descendente ela se localiza no início; e na ascendente, que se configura no sentido de uma análise genealógica, ela surge no final. Ambas são necessárias porquanto o princípio de universalização moral U não pode ser inferido apenas de pressuposições da argumentação, as quais são normativas em sentido transcendental (HABERMAS, 2005) ${ }^{6}$.

\section{CONCLUSÃO}

As considerações acima apresentadas sugerem, em primeiro lugar, que a ética do discurso ou teoria discursiva da moral precisa ser bem entendida. De um lado, tendo em vista o fato de que esse programa pós-metafísico se circunscreve a questões de justiça, ele não possui a capacidade de criar valores éticos ou normas morais vinculantes, que é tarefa das próprias pessoas afetadas por conflitos morais e que procuram solução em deliberações argumentativas. Em que pese isso, julgo conveniente terminar minhas reflexões chamando a atenção para o fato de que Habermas aparentemente desafia seu próprio postulado de abstenção relativo à criação de normas morais e éticas quando se pergunta, em $\mathrm{O}$ futuro da natureza humana se tal abstenção se justifica também ante as atuais técnicas de manipulação genética que estão a exigir uma "ética da espécie humana" baseada em juízos de valor. Tal ética da espécie deveria ser compartilhada por todas as pessoas morais antes mesmo de entrarem em procedimentos argumentativos sobre normas morais questionadas. (HABERMAS, 2001)

Quero encerrar lembrando que a ética do discurso, apesar de seu caráter inconcluso e procedimental, sempre deixou bem claro que pretende "abrir os olhos" dos céticos para a importância dos fenômenos éticos e morais e para a necessidade da justificação racional destes fenômenos. Ela se coloca, assim, frontalmente contra qualquer tipo de relativismo. De outro

\footnotetext{
${ }^{6}$ No meu entender, o seguinte esquema tripartite consegue sistematizar os pontos essenciais da argumentação habermasiana em prol do princípio moral 'U' contidos nesse texto:

1 Habermas constata que o princípio de universalização moral ' $U$ ' não pode ser inferido exclusivamente de pressuposições transcendentais da argumentação.

2 Ele introduz uma distinção entre:

2.1. O conteúdo normativo de pressuposições transcendentais, inevitáveis, da argumentação.

2.2. O sentido de validade que tem a ver com aspectos de validade à luz dos quais é possível explorar pressuposições de uma argumentação ou discurso.

3 O sentido de obrigatoriedade, isto é, o "ter de" deontológico do princípio moral é resultado de uma conexão entre 2.1. e 2.2. Cf. Id, Die Einbeziehung des Anderen, 11-64.
} 
lado, ela pretende desenvolver uma nova visão capaz de incluir o outro, o diferente, o estranho, o estrangeiro, o excluído.

\section{REFERENCIAS}

APEL, Karl-Otto. Das Apriori der Kommunikationsgemeinschaft und die Grundlagen der Ethik, in: Id. Transformation der Philosophie, Vol II, Frankfurt? M.: Suhrkamp, 1973. APEL, Karl-Otto.Grenzen der Diskursethik. Versuch einer Zwischenbilanz, in: Zeitschrift für philosophische Forschung, Band 40, Heft. 1, 1986, 3-31.

APEL, Karl-Otto. Auseinandersetzungen in Erprobung des transzendentalpragmatischen Ansatzes. Frankfurt/M.: Suhrkamp, 1998.

APEL, Karl-Otto. Etnoética e macroética universalista: oposição ou complementaridade?, in: Ethica. Cadernos Acadêmicos, Vol. 4, n. 2, 1997.

APEL, Karl-Otto. Diskurs und Verantwortung. Das Problema des Übergangs zur postkonventionellen Moral. Frankfurt/M.: 1988.

BÖHLER, Dietrich. (ed.) Ethik für die Zukunft. Munique: C H. Beck, 1994.

HABERMAS, Jürgen. Moralbewusstsein und Kommunikatives Handeln. Frankfurt/M.: Suhrkamp, 1983.

HABERMAS, Jürgen. Erläuterungen zur Diskursethik. Frankfurt/M.: Suhrkamp, 1991. HABERMAS, Jürgen. Faktizität und Geltung. Beiträge zur Diskurstheorie des Rechts und des demokratischen Rechtsstaats. Frankfurt/M.: Suhrkamp, 1992.

HABERMAS, Jürgen. Die Einbeziehung des Anderen. Studien zur politischen Theorie. Frankfurt/M.: Suhrkamp, 1996.

HABERMAS, Jürgen. Wahrheit und Rechtfertigung. Philosophische Aufsätze.

Frankfurt/M.: Suhrkamp, 1999.

HABERMAS, Jürgen. Die Zukunft der menschlichen Natur. Auf dem Weg zu einer liberalen Eugenik?. Frankfurt/M.: Suhrkamp, 2001.

HABERMAS, Jürgen. Zwischen Naturalismus und Religion. Philosophische Aufsätze. Frankfurt/M.: Suhrkamp, 2005.

JONAS, Hans. Das Prinzip Verantwortung. Versuch einer Ethik für die technologische Zivilisation. Frankfurt/M.: Insel Verlag, 1979.

KUHLMANN, Wolfgang. Prinzip Verantwortung versus Diskursethik, in BÖHLER, D. (ed.) Ethik für die Zukunft. Munique: C.H. Beck, 1994.

RAWLS, John. A Theory of Justice. Harvard, 1971.

SIEBENEICHLER, Flávio Beno. O papel da análise genealógica no cognitivismo moral de J. Habermas, in: Ethica. Cadernos Acadêmicos, Vol 5, n, 2, 1998, 24-40.

SIEBENEICHLER, Flávio Beno. A filosofia perante os desafios da ética num mundo globalizado: ética da preservação versus ética do discurso, in: Ethica. Cadernos Acadêmicos, Vol. 6, n. 2, 1999, 130-149.

SIEBENEICHLER, Flávio Beno. A ética do discurso à luz das re visões dos seus fundadores pós-kantianos, in: Ethica. Cadernos Acadêmicos, Vol. 7, n. 2, 2000, 37-52. 
TUGENDHAT, Ernst. Vorlesungen über Ethik. Frankfurt/M.: Suhrkamp, 1993.

WELLMER, Albrecht. Ethik und Dialog. Elemente des moralischen Urteils bei Kant und in der Diskursethik. Frankfurt/M.: Suhrkamp, 1986.

WINGERT, Lutz. Gemeinsinn und Moral. Grundzüge einer intersubjektivistischen Moralkonzeption. Frankfurt/M.: Suhrkamp, 1993.

ZIMMERLI, Ch. Walter. Philosophie in einer Gott-verlassenen Welt, in BÖHLER, Dietrich (ed.) Ethik für die Zukunft. Munique: C.H. Beck, 1994. 